Reprod. Nutr. Dévelop., 1987, 27 (1 B), 197-198.

\title{
L'ingestion des fourrages des parcours naturels en zone sahélienne : mesures en stabulation et au pâturage
}

\author{
H. GUERIN, D. FRIOT, Nd MBAYE, S. T. FALL, D. RICHARD (*) \\ avec la collaboration de M. DIOP, A. CORREA, I. NDIAYE, T. M. BA \\ Laboratoire de /'Elevage et de Recherches vétérinaires (I.S.R.A.) \\ B.P. 2057, Dakar-Hann, Sénégal. \\ ${ }^{*}{ }^{*}$ Institut d'Elevage et de Médecine vétérinaire des Pays tropicaux (C.I.R.A.D.) \\ 10, rue Pierre Curie, 94704 Maisons-Alfort Cedex, France.
}

\begin{abstract}
Summary. Sheep voluntary intake of forages harvested in Sahelian natural pastures was measured in pens. The oesophageal boluses and total fecal excretions of sheep and cattle were collected simultaneously in order to estimate intake in the same pastures. The differences between indoor and outdoor measurements and between seasons and species have been analysed.
\end{abstract}

La production, la composition floristique et chimique des fourrages des parcours naturels et du régime des ruminants sahéliens varient beaucoup d'une région, d'une année et d'une saison à l'autre (Guerin et al., 1986 ; Richard et al., 1985). Pour apprécier la digestibilité et les quantités ingérées de ces fourrages, des mesures ont été faites dans la région du Ferlo au Sénégal simultanément sur des moutons et des bovins qui les pâturaient et sur des moutons en cage qui les recevaient fauchés.

Matériel et méthodes. Le parcours étudié était une parcelle de 740 hectares du ranch de Doli appartenant à la SODESP (Société de Développement de l'Elevage en Zone Sylvopastorale). Sa production a été de $2000 \mathrm{~kg} \mathrm{MS} / \mathrm{ha}$ en 1981, de $1300 \mathrm{~kg}$ de MS/ha en 1982 et les quantités de biomasse disponibles en fin de saison sèche étaient respectivement de 1400 et $700 \mathrm{~kg}$ de MS/ha. Il était exploité principalement par des zébus Gobra (100 à 150 suivant les périodes) en croissance dont le poids a varié entre 125 et $350 \mathrm{~kg}$ et accessoirement par trente béliers de race peul-peul également en croissance de 25 à $35 \mathrm{~kg}$ de poids vif. La charge a été en moyenne de $35 \mathrm{~kg}$ de poids vif par hectare.

Sur des groupes de 6 béliers entiers en cages individuelles, on a étudié à un rythme mensuel 27 échantillons de fourrage fauché. En saison des pluies le fourrage était fauché quotidiennement, en saison sèche en une seule fois pour chaque essai. Conservé à l'air libre, il était distribué en 2 ou 3 repas à volonté, avec des taux de refus élevés ( 25 à $40 \%$ ) pour reproduire les possibilités de tri des animaux au pâturage. Après deux semaines d'adaptation des moutons au régime, on mesurait pendant 6 jours la quantité de matière sèche volontairement ingérée (MSVI) et la digestibilité de la matière organique (dMO).

La valeur alimentaire des fourrages ingérés par les animaux au pâturage a été étudiée par des méthodes indirectes faisant appel, notamment, à des prélèvements de bols œsophagiens, des échantillons de "collecte du berger " (Richard et al., 1985) et à la collecte totale des fèces (Dicko et al., 1981). L'excrétion fécale au pâturage a été mesurée au cours de 37 essais de 5 jours sur 8 moutons et de 55 essais sur 5 bovins. 
Résultats et discussion. La teneur en matière sèche (fig. 1) des fourrages n'est inférieure à $90 \%$ que durant les 3 à 4 mois de saison humide, période où les MSVI et la dMO ont été les plus élevées, respectivement $70 \mathrm{~g} \mathrm{MS} / \mathrm{kg} \mathrm{P0,75}$ et $70 \%$. Durant la saison sèche, les fourrages ne sont constitués que des pailles sur pied dont la composition et la digestibilité varient peu. Cependant, les quantités ingérées par les moutons en cages diminuent en fin de saison sèche sous les effets conjugués des conditions climatiques sévères et aussi probablement de la dégradation de l'état physiologique des animaux.

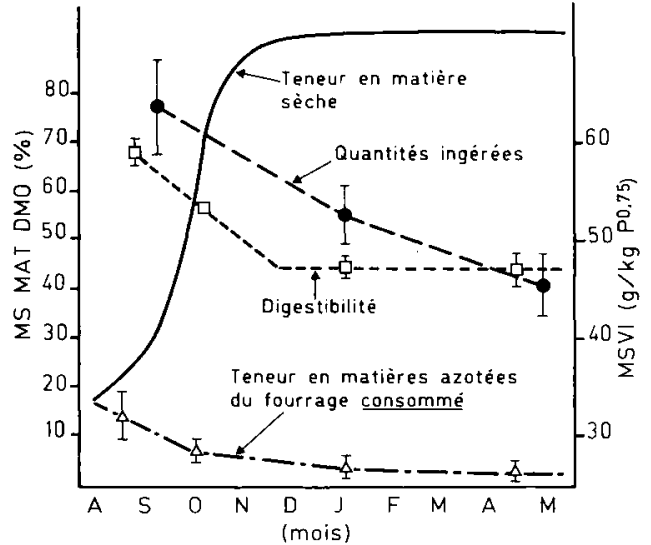

FIG. 1 .

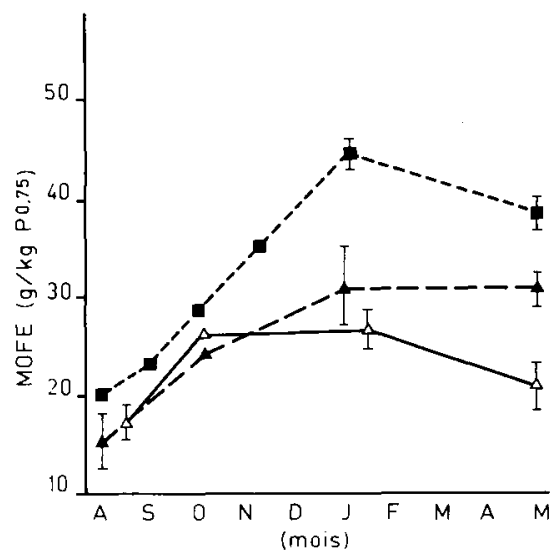

FIG. 2.

FIG. 1. - Moyennes mensuelles ou saisonnières de la composition (MS : —_ ; MAT: $\triangle$ ), de la digestibilité (DMO : $\square$ ) et des quantités ingérées (MSVI : @) du fourrage fauché et distribué à des moutons en cages. FIG. 2. - Quantité de matière organique fécale excrétée (MOFE) par des moutons en cages $(\triangle)$, des moutons $(\mathbf{\Lambda})$ et des bovins $(\mathbf{Q})$ au pâturage à Doli.

Les teneurs en matières azotées totales (MAT) des fourrages ingérés par les bovins $(67 \pm 7 \mathrm{~g} / \mathrm{kg}$ de MS pour les bols œsophagiens et $55 \pm 7$ pour la « collecte du berger $\gg)$ et les ovins ( $85 \pm 5$ et $64 \pm 5$ respectivement) au pâturage sont supérieures à celles mesurées pour les moutons en cages (44 \pm 10$)$. II en est de même pour les teneurs en MAT des fèces : $120 \pm 9 \mathrm{~g} / \mathrm{kg}$ de MS, $95 \pm 9$ et $78 \pm 5$ respectivement. La digestibilité des fourrages ingérés au pâturage est donc supérieure à celle des fourrages ingérés par les moutons en cages.

De plus, l'excrétion de matière organique fécale supérieure au pâturage (fig. 2) traduit une ingestion de fourrage plus élevée qu'en stabulation qui explique les gains de poids des moutons tout au long de la saison sèche (40 à $50 \mathrm{~g} / \mathrm{j}$ ) alors que la valeur alimentaire du fourrage mesurée à l'auge est en moyenne faible. Les bovins moins aptes au tri que les petits ruminants ont un régime plus pauvre en azote que les ovins, et leur ingestion diminue à partir de mars-avril. Leur croissance s'interrompt alors, ou ils perdent du poids ( - $100 \mathrm{~g} / \mathrm{j})$ même si le fourrage est abondant.

L'estimation de la digestibilité des bols œesophagiens et des collectes du berger par des méthodes chimiques ou enzymatiques permettra de préciser les quantités ingérées au pâturage.

Dicko M. S. et al., 1981. 32é réunion Fédération Européenne de Zootechnie, Zagreb, 31 août, 3 septembre 1981.

Guerin H. et al., 1986. Reprod. Nutr. Dévelop., 26, 269-270

Richard D. et al., 1985. 36e réunion Fédération Européenne de Zootechnie, Kallithea (Grèce), 30 septembre, 3 octobre 1985. 